\title{
Cerebrospinal fluid acetylcholinesterase in progressive supranuclear palsy: reduced activity relative to normal subjects and lack of inhibition by oral physostigmine
}

John R Atack, Irene Litvan, Leon J Thal, Conrad May, Stanley I Rapoport, Thomas N Chase

\begin{abstract}
Acetylcholinesterase (AChE) activity was measured in lumbar cerebrospinal fluid (CSF) of 11 patients with progressive supranuclear palsy (PSP) and 18 age-matched healthy control subjects. Mean CSF AChE activity in PSP subjects was significantly reduced by $31 \%$ relative to control subjects $(p<0.002)$. In the light of evidence of a central cholinergic deficit, physostigmine was administered orally $(0 \cdot 5-2 \cdot 0 \mathrm{mg}$ every two hours, six times a day for 10 days) to eight of the 11 PSP patients. CSF was sampled when the patients were on placebo and when receiving physostigmine and CSF AChE and butyrylcholinesterase (BChE) activities were measured. There was no significant change in either CSF AChE or BChE activities following physostigmine treatment. These data suggest that the doses of physostigmine used were insufficient to produce marked inhibition of $\mathrm{AChE}$ within the central nervous system.
\end{abstract}

Neurosciences,

National Institute on

Aging

J R Atack

C May

S I Rapoport

Experimental

Therapeutics Branch,

National Institute of

Neurological and

Communicative

Disorders and Stroke,

National Institutes of

Health, Bethesda,

Maryland

I Litvan

T N Chase

Neurology Service,

San Diego VA Medical

Center, San Diego,

California, USA

L J Thal

Correspondence to:

Dr Atack, Merck Sharp and

Dohme, Neuroscience

Research Centre, Terlings

Park, Eastwick Road,

Harlow, Essex CM20 2QR,

UK.

Received 17 August 1990

and in revised form

7 January 1991.

Accepted 2 February 1991 pathologically, there is neuronal degeneration and neurofibrillary tangles (which are distinct from those seen in Alzheimer's disease) in the pontine tegmentum, dentate nucleus, red nucleus, substantia nigra, subthalamic nucleus and globus pallidus. ${ }^{1}$ Neurochemically, there is degeneration of the nigrostriatal dopaminergic system, similar to that seen in Parkinson's disease, which is thought to result in the Parkinsonian extrapyramidal features of PSP. ${ }^{12}$ However, and in contrast to Parkinson's disease, the mesolimbic and mesocortical dopaminergic projection systems seem to be relatively spared in PSP. ${ }^{12}$

So far as the central cholinergic systems are concerned, there is a loss of large, probably cholinergic $^{3}$ neurons in the striatum ${ }^{4}$ and reduced levels of striatal choline acetyltrans- ferase activity have been reported. ${ }^{5}$ Degenerative changes are also seen in the cholinergic basal forebrain, ${ }^{56}$ although alterations in cortical choline acetyltransferase activity ${ }^{57}$ and nicotinic receptor binding ${ }^{8}$ are more variable and less severe than those seen in Alzheimer's disease. ${ }^{9}$ In addition, there is a marked degeneration of the hindbrain pedunculopontine tegmental nucleus pars compacta, ${ }^{10}$ a putative cholinergic nucleus which projects to many nuclei of the extrapyramidal system. ${ }^{11}$

The purpose of this study was to determine whether reported postmortem deficits in central cholinergic systems in PSP are reflected in vivo by changes in cerebrospinal fluid (CSF) acetylcholinesterase (AChE) activity. Furthermore, PSP subjects were also given oral physostigmine in a double-blind cross-over study and, as an index of the CNS AChEinhibitory effects of physostigmine treatment, CSF AChE activities were measured following physostigmine treatment and were compared to activities following placebo. In addition, CSF butyrylcholinesterase (BChE) was also measured since, although this enzyme is not related to central cholinergic function and probably derives from plasma, it is nevertheless sensitive to physostigmine. Consequently, the measurement of $\mathrm{BChE}$ activity following physostigmine administration serves as an additional index of whether sufficient drug enters the CNS and produces cholinesterase inhibition.

\section{Patients and methods}

Subject selection

The clinical diagnosis of PSP was made in 11 subjects [five men and six women; mean (SD) age 64 (6) years] according to: 1) age at onset greater than 50 years; 2) extraocular movement abnormalities characterised by supranuclear vertical (with or without horizontal) palsy;12 3) Parkinsonian signs (including bradykinesia, postural or gait instability, axial dystonia and rigidity) in the absence of resting tremor; 4) pseudobulbar signs, including dysarthria and dysphagia; and 5) progressive course. The mean (SD) duration of symptoms was 35 (13) months. During 
this study no subjects received centrallyacting drugs except one who continued to receive levodopa-carbidopa. Parkinsonian rigidity and akinesia was generally mild to moderate [Columbia Rating Scale (SD) 11 (4) range 5-18] and dementia was generally mild [Mattis Dementia Rating Scale, 123 (8) range 112-139; Weschler Memory Quotient, 96 (10) range 79-110]. Healthy control subjects [11 male, seven female; mean (SD) age 65 (10) years] were selected according to criteria described elsewhere. ${ }^{13}$

\section{Physostigmine treatment}

Physostigmine treatment was as described previously. ${ }^{14}$ Briefly, eight of the 11 PSP patients received escalating doses of physostigmine six times daily $(0.5 \mathrm{mg}$ per dose on day 1 rising to $2.0 \mathrm{mg}$ per dose on day 4 ). The Buschke Selective Reminding Test ${ }^{15}$ was used to assess the best dose for each individual. Patients were subsequently randomised to a 10 day, placebo-controlled, doubleblind, cross-over trial of physostigmine. Each individual received their previously determined best dose [mean (SD) $1.25(0.46) \mathrm{mg}$ / dose, range $0.5-2.0 \mathrm{mg} /$ dose] six times a day at two hour intervals.

\section{Lumbar puncture}

Cerebrospinal fluid was collected on the tenth day of placebo or physostigmine treatment at approximately $8.30 \mathrm{am}$ (about 30 minutes after the second morning dose). CSF was also collected at a similar time from the three PSP patients not admitted into the physostigmine study. CSF was removed from healthy normal subjects $^{13}$ using procedures comparable to those employed for the PSP patients. CSF was immediately frozen on dry ice and kept at $-70^{\circ} \mathrm{C}$ until assayed.

\section{Assay procedures}

Acetylcholinesterase and $\mathrm{BChE}$ activities were assayed as described previously. ${ }^{13}$ Thus $0.5 \mathrm{mM}$ acetyl- $\beta$-methylthiocholine and $0.5 \mathrm{mM}$ butyrylthiocholine were used as relatively specific substrates for the assay of $\mathrm{AChE}$ and BChE activity, respectively. The coefficient of variation of the AChE assay was $2.9 \%$ and that for $\mathrm{BChE}$ was $2.4 \%$. Total protein concentrations were determined by the method of Lowry et al. ${ }^{16}$

In the event that physostigmine administration produced inhibition of CSF AChE and $\mathrm{BChE}$ activities, an indirect method was devised to estimate CSF physostigmine concentrations. Thus increasing concentrations of physostigmine were incubated with samples of CSF from three normal and three PSP subjects. The percentage activity was plotted as a function of physostigmine concentration and from these "standard curves" it was possible to predict the CSF physostigmine concentration corresponding to any given $\%$ inhibition of CSF AChE or BChE activity. CSF physostigmine concentrations were also measured directly using a modification of a high-performance liquid chromatography (HPLC) method. ${ }^{17}$ This assay has a sensitivity of $0.05 \mathrm{ng} / \mathrm{ml}$.

Values shown are mean (SD). Comparisons between groups were made using Student's $t$ test and the level of significance was taken as $\mathrm{p}<0.05$.

\section{Results}

AChE activities in PSP and healthy control subjects

The figure shows AChE activity in control and PSP subjects. In PSP, CSF AChE activity was significantly reduced by $31 \% \quad(p<0.002)$ relative to control values $[14 \cdot 7(5 \cdot 1)$ and $21 \cdot 3$ $(4 \cdot 8) \mathrm{nmol} / \mathrm{min} / \mathrm{ml}$, respectively]. Neither BChE activity nor total protein concentrations differed significantly between groups [BChE activity $=10.0(3.0)$ and $9.4(3.6) \mathrm{nmol} /$ $\mathrm{min} / \mathrm{ml}$; protein $=0.56(0.15)$ and $0.55(0.18)$ $\mathrm{mg} / \mathrm{ml}$ in control and PSP groups, respectively].

\section{Effect of physostigmine on AChE and BChE activities}

Physostigmine treatment had no significant effect on either AChE or BChE activity in CSF of PSP patients. Following treatment, AChE activity (SD) was $98(5 \%)$, and BChE $97(8 \%)$ of activity observed following placebo administration.

To estimate the CSF physostigmine concentration, $\mathrm{AChE}$ and $\mathrm{BChE}$ activities were measured as a function of physostigmine concentration. The $\mathrm{IC}_{50}$ of physostigmine versus $\mathrm{AChE}$ and $\mathrm{BChE}$ did not differ between control and PSP CSF and was 30-40 nM for both enzymes. Given the relatively small variations in $\mathrm{AChE}$ and $\mathrm{BChE}$ activities during the 10 day period between placebo and physostigmine lumbar punctures, as well as the small coefficient of variation of the assays $(<3 \%)$, we estimated that we could have reliably detected a $10 \%$ enzyme inhibition, which would correspond to a physostigmine concentration of 1$2 \mathrm{nM}$. Therefore since we could not detect any change in either AChE or BChE activities following physostigmine treatment, CSF physostigmine concentrations must have been less than $1-2 \mathrm{nM}(0.28-0.55 \mathrm{ng} / \mathrm{ml}$ free base).

In addition, CSF physostigmine concentrations were also measured directly using HPLC.

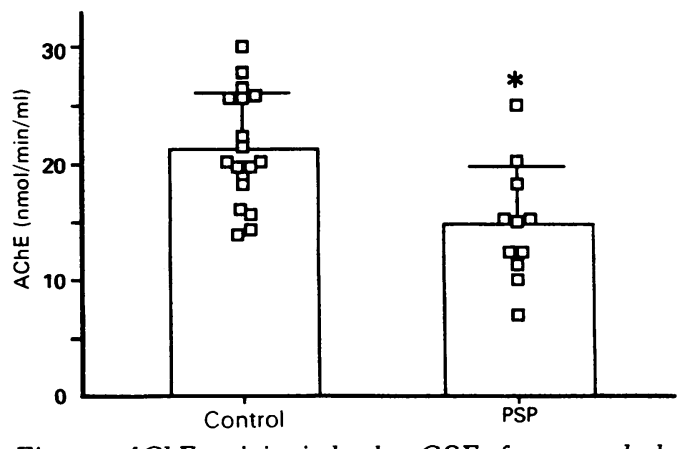

Figure AChE activity in lumbar CSF of age-matched healthy control subjects and PSP patients. AChE activity was significantly lower $(\star, p<0.002)$ in PSP patients (mean (SD) AChE activity = 14.7 (5.1) nmol $/ \mathrm{min} / \mathrm{ml} /$ compared with control subjects [21.3 (4.8) $\mathrm{nmol} / \mathrm{min} / \mathrm{ml} /$. 
In two of the eight patients studied, physostigmine concentrations were below the limits of detection $(<0.05 \mathrm{ng} / \mathrm{ml})$. In the other six, physostigmine concentrations ranged from $0.07-0.35 \mathrm{ng} / \mathrm{ml}$. There was, however, no correlation between CSF physostigmine concentrations and the dose administered, that is, patients with the highest CSF physostigmine concentrations were not necessarily the patients receiving the highest oral doses $(1.5$ or $2.0 \mathrm{mg} /$ dose). These data are in good agreement with the physostigmine concentrations estimated from the activity versus physostigmine concentration curves (less than $0.28-0.55 \mathrm{ng} / \mathrm{ml})$.

\section{Discussion}

AChE activity in PSP and healthy control subjects

Reduced CSF AChE activity in PSP is consistent with a central cholinergic deficit in these patients. However, reduced CSF AChE activity in PSP is unlikely to be solely due to degeneration of the cholinergic basal forebrain projection. Thus in PSP the degeneration of these systems and consequent loss of cortical cholinergic markers ${ }^{5-8}$ is less pronounced than in Alzheimer's disease ${ }^{9}$ yet the reduction in CSF AChE activity in PSP is greater than that observed in Alzheimer's disease. ${ }^{13}$

Reduced CSF AChE activity in PSP may also be partly related to degeneration of the cholinergic pedunculopontine nucleus, ${ }^{10}$ which projects to many nuclei of the extrapyramidal system. In addition, the loss of cholinergic activity in the striatum, ${ }^{5}$ whether it be as a consequence of loss of putative cholinergic input from the pedunculopontine nucleus or a degeneration of intrinsic cholinergic neurons ${ }^{45}$ may also contribute to reduced lumbar CSF AChE activity in PSP. CSF AChE activity may be relatively sensitive to changes in striatal cholinergic function given the high $\mathrm{AChE}$ content of the striatum ${ }^{18}$ and the proximity of the striatum to CSF in the cerebral ventricles.

Effect of physostigmine on AChE and BChE activities

Since peak plasma physostigmine concentrations are achieved 20-40 minutes after oral administration $^{1719}$ and the time course of physostigmine in rat brain (and presumably CSF) parallels that of plasma, ${ }^{20}$ we chose 30 minutes as an optimum time to sample CSF after oral administration of physostigmine to PSP patients. However, following oral administration of $0.5-2.0 \mathrm{mg}$ physostigmine, no effect on CSF AChE or BChE activity was observed. In contrast, using dosing schedules similar to those employed in this study, CSF AChE inhibition as high as $70 \%$ has been reported following oral doses of $1-3.5 \mathrm{mg}$. $^{21}$ This discrepancy may be related in part to methodological differences. Thus in this study, CSF $\mathrm{AChE}$ and $\mathrm{BChE}$ activities after physostigmine treatment were compared with activities after placebo treatment, whereas in previous studies the degree of CSF AChE inhibition was assessed using a reactivation analysis in which
CSF was incubated at $37^{\circ} \mathrm{C}$ for two to 28 hours. $^{21}$

The direct measurement of CSF physostigmine concentrations by HPLC revealed CSF levels, where detectable, of between 0.07 and $0.35 \mathrm{ng} / \mathrm{ml}$. At these physostigmine concentrations, CSF AChE activity would be inhibited by less than $10 \%$ and would therefore explain why inhibition of $\mathrm{AChE}$ (or BChE) could not be detected in our study. Moreover, the indirect estimation of CSF physostigmine concentration (using activity versus physostigmine concentration curves) of less than 1-2 $\mathrm{nM}$ (less than $0.28-0.55 \mathrm{ng} / \mathrm{ml}$ ) agrees well with the physostigmine concentrations measured directly using HPLC (less than $0.35 \mathrm{ng} / \mathrm{ml}$ ). This suggests that this indirect method is a useful means of estimating CSF physostigmine concentrations, not only since it measures the pharmacodynamics (\% inhibition of $\mathrm{AChE}$ ) rather than the pharmacokinetics (drug concentration) of physostigmine, but also because it is a relatively straightforward, reproducible and inexpensive means for determining CSF concentrations of physostigmine or, indeed, any other cholinesterase inhibitor, for example, tetrahydroaminoacridine (THA).

The lack of pronounced inhibition of CSF (and presumably brain) AChE by doses of $0.5-$ $2.0 \mathrm{mg}$ physostigmine may explain the relatively modest and inconsistent behavioural changes observed in these patients. ${ }^{14}$ In future, the use of controlled release physostigmine preparations, resulting in sustained plasma physostigmine levels ${ }^{22}$ or the development of novel physostigmine analogues ${ }^{23}$ may prove to be more useful in the modulation of central cholinergic activity.

1 Lees AJ. The Steele-Richardson-Otszewski syndrome (progressive supranuclear palsy). In: Marsden CD, Fahn
S, eds. Movement Disorders 2. London: Butterworths, S, eds. Moveme

2 Young AB. Progressive supranuclear palsy: postmortem chemical analysis. Ann Neurol 1985;18:521-2.

3 Parent A, Csonka C, Etienne P. The occurrence of large acetylcholinesterase-containing neurons in human neostriatum as disclosed in normal and Alzheimer-discased brains. Brain Res 1984;291:154-8.

4 Oyanagi K, Takahashi H, Wakabayashi K, Ikuta F. Selective decrease of large neurons in the neostriatum in progressive supranuclear palsy. Brain Res 1988;458: 218-23.

5 Ruberg M, Javoy-Agid F, Hirsch E, et al. Dopaminergic and cholinergic lesions in progressive supranuclear palsy. $A m n$ Neurol 1985;18:523-9.

6 Tagliavini F, Pilleri G, Gemignani F, Lechi A. Neurongl loss in the besal nucleus of Meynert in progressive supranuclear palsy. Acta Neuropathol 1983;61:157-60.

7 Kish SJ, Chang LJ, Mirchandani L, Shannak K, Hornykiewicz O. Progressive supramuclear palsy: Relationship between extrapyramidal disturbances, dementia, and brain neurotransmitter markers. Ann Neurol 1985; 18:530-6.

8 Whitehouse PJ, Kellar KJ. Nicotinic and muscarinic cholinergic receptors in Alzheimer's disease and related disorders. J Neurol Transm 1987;24(Suppl): 175-82.

9 Perry EK. The cholinergic hypothesis-ten years on. $\mathrm{Br}$ Med Bull 1986;A2:63-9.

10 Hirsch EC, Graybiel AM, Duyckaerts C, Javoy-Agid F Neuronal loss in the pedunculopontine tegmental nucleus in Parkinson disease and in progressive supranuclear palsy. Proc Natl Acad Sci (USA) 1987;84:5976-80.

11 Saper CB, Loewy AD. Projections of the pedunculopontine tegmental nucleus in the rat: Evidence for additional extrapyramidal circuitry. Brain Res 1982;252:367-72.

12 FitzGibbon EJ, Carl JR, Litvan I. Horizontal, vertical, and oblique saccades in progressive supranuclear palsy. Invest
of oblique saccades in progressive sup
Opthalmol Vis Sci 1988;29:344.

13 Atack JR, May C, Kaye JA, Kay AD, Rapoport SI. Cerebrospinal fluidecholinesterases in aging and in dementia of the Alzheimer type. Ann Neurol 1988;23:161-7.

14 Litvan I, Gomez C, Atack JR, et al. Physostigmine treatment of progressive supranuclear palsy. Ann Neurol 1989; of progres

15 Buschke H, Fuld PA. Evaluating storage, retention, and 
retrieval in disordered memory and learning. Neurology 1974;24:1019-25.

16 Lowry OH, Rosebrough NJ, Farr AL, Randall RJ. Protein measurement with the Folin phenol reagent. J Biol Chem 1951;193:265-75

17 Sharpless NS, Thal LJ. Plasma physostigmine concentrations after oral administration. Lancet 1985;i:1397-8

18 Atack JR, Perry EK, Bonham JR, Candy JM, Perry RH. Molecular forms of acetylcholinesterase and butyrylcholinesterase in the aged human central nervous system. $J$ Neurochem 1986;47:263-77.

19 Whelpton R, Hurst P. Bioavailability of oral physostigmine.

20 Somani SM, Khalique A. Pharmacokinetics and pharma- codynamics of physostigmine in the rat after intravenous administration. Drug Metab Disposition 1987;15:627-33.

21 Thal LJ, Masur DM, Sharpless NS, Fuld PA, Davies P. Acute and chronic effects of oral physostigmine and lecithin in Alzheimer's disease. Prog Neuro-Psychopharmacol Biol Psychiatry 1986;10:627-36.

22 Tharmacol Biol Psychiatry 1986;10:627-36. Nigalye A. Plasma physostigmine concentrations after Nigalye A. Plasma physostigmine concentrations after
controlled-release oral administration. Arch Neurol 1989; 46:13.

23 Atack JR, Yu Q-S, Soncrant TT, Brossi A, Rapoport SI. Comparative inhibitory effects of various physostigmine analogs against acetyl- and butyrylcholinesterases. $J$ Pharmacol Exp Therap 1989;249:194-202. 